\title{
Feasibility Study on the Etherification of Fermentative-Produced Isobutylene to Fully Renewable Ethyl Tert-Butyl Ether (ETBE)
}

\author{
Maik Tretbar ${ }^{1}$, Thomsen Witzel ${ }^{1}$, Anika Hauffe ${ }^{1}$, Ulrike Junghans ${ }^{1}$, Aleš Bulc ${ }^{2}$ and \\ Daniela Pufky-Heinrich 1,* \\ 1 Fraunhofer Center for Chemical-Biotechnological Processes CBP, Am Hauptor Bau 1251, 06237 Leuna, \\ Germany; maik.tretbar@uni-leipzig.de (M.T.); thomsenwitzel@gmail.com (T.W.); \\ ani_hauffe@live.de (A.H.); ulrike.junghans@igb.fraunhofer.de (U.J.) \\ 2 Global Bioenergies GmbH, Am Hauptor Bau 4310, 06237 Leuna, Germany; ales.bulc@global-bioenergies.com \\ * Correspondence: daniela.pufky-heinrich@cbp.fraunhofer.de; Tel.: +49-3461-439103; Fax: +49-3461-43999
}

Received: 25 September 2018; Accepted: 2 November 2018; Published: 3 November 2018

\begin{abstract}
This work evaluates the direct etherification of bio-sourced isobutylene with ethanol forming fully renewable ethyl tert-butyl ether (ETBE). Challenge was the use of the fermentative produced substrate in a solvent-free catalysis using the acidic ion exchanger Amberlyst- 15 . $\mathrm{CO}_{2}$ impurities have a significant influence on the liquid phase process. The conversion at a ratio that is based on molarities of isobutylene to ethanol of 1:0.9 results in yields up to $97 \mathrm{~mol} \%$ ETBE. Purities up to $99 \mathrm{wt} . \%$ could be achieved by subsequent water extraction in order to ensure qualities for technical application as high performance fuel additive.
\end{abstract}

Keywords: ethyl tert-butyl ether (ETBE); biofuel additive; bio-sourced isobutylene; etherification; Amberlyst-15

\section{Introduction}

The reduction of $\mathrm{CO}_{2}$ emissions and other pollutants, especially in the transport sector, is of central importance for a sustainable energy management. A limit value of $95 \mathrm{~g} \mathrm{CO}_{2} / \mathrm{km}$ is set for new licensed vehicles [1]. Hence, liquid fuels and fuel additives that are based on biomass are increasingly in focus of research. To date, mainly alcohol-based biofuels, such as bioethanol in Otto engines or fatty acid methyl esters as biodiesel in diesel vehicles are used. However, these biofuels can only be blended to conventional fossil fuels in limited amounts in order to avoid technical incompatibilities. A promising candidate to overcome this so-called blend wall of bioethanol is ETBE. When compared to methyl tert-butyl ether (MTBE), it has less critical environmental impact $[2,3]$ and it can be blended up to $47 \%$ [4]. Moreover, ethyl tert-butyl ether (ETBE) provides nearly triple the alternative energy value than the direct blending of ethanol into fuels [5].

Partially renewable ETBE is obtained by the reaction of renewable ethanol with a molecule of fossil isobutylene. This is already used in vehicles, up to a maximum of $23 \mathrm{wt} . \%$ possessing a global market valued with more than $€$ two billion and three billion tons annually [6]. One attempt has already been made to produce completely bio-sourced ETBE fuel additive using bio-sourced isobutylene. In 2015, Sun et al. [7] has been shown the pioneering work to produce completely bio-based ETBE fuel additive from acetic acid prepared in the presence of a $\mathrm{Zn} / \mathrm{ZrO}$ catalyst. Bio-sourced isobutylene can also be produced directly from sugar and lignocellulose-based biomass by bacterial fermentative processes utilizing a genetically engineered microorganism [8-11]. Renewable resources, such as sugar, cereals, agricultural, and forestry waste are available in huge amounts for such sustainable application. 
Subsequent conversion to fuels and fuel additives, e.g., isooctane, MTBE, ETBE, or alkylates, are in focus of recent investigations. The mentioned additives improve the quality of raw gasoline blends that are produced in refineries, especially regarding the octane number, knock resistance, energy density, and the associated increase in range, respectively [12].

Generally, ETBE has been formed via an exothermic electrophilic addition reaction of ethanol and isobutylene using heterogeneous catalysts [13]. Shpantseva et al. [14] describe a process in which isobutylene containing hydrocarbon mixtures are converted with ethanol at $30^{\circ} \mathrm{C}$ to $100{ }^{\circ} \mathrm{C}, 0.5 \mathrm{MPa}$ to $2.0 \mathrm{MPa}$, and a space velocity of $3.5 \mathrm{~h}^{-1}$ to $10 \mathrm{~h}^{-1}$ to ETBE via an acidic ion exchange catalyst. The molar ratio of ethanol to isobutylene was varied from $0.95: 1$ to 1.1:1. Goto et al. [15,16] describe a method for the conversion of isobutylene and water containing C4 fractions with ethanol, in which isobutylene reacts with water to form tert-butanol and with ethanol to give ETBE using a solid-state catalyst. The used catalyst Amberlyst-15 is a macroreticular structured polystyrene divinylbenzene matrix containing strongly acid sulfonic acid groups. Alternatively, $\beta$-zeolite can be used. When compared to Amberlyst-15, a reduced catalytic activity was found, but with a significantly higher selectivity [17].

Etherification to MTBE and ETBE are well known in the industrial scale and utilize isobutylene fractions from FCC (fluid catalytic cracking), steam cracking or isobutylene dehydrogenation processes. Here, isobutylene is diluted with saturated C4-mixtures containing max. $55 \mathrm{wt} . \%$ isobutylene. Unreactive components act as a solvent in order to decrease the stoichiometry of the reactive gas, and thus, to control the exothermic nature of the reaction $[18,19]$. However, this concept cannot be pursued to avoid contamination of the substrate.

The goal of this study was the first evaluation of ETBE synthesis from fermentative generated isobutylene in order to produce a purely biogenic product fraction, and, in consequence, providing a neutral $\mathrm{CO}_{2}$ balance. Accordingly, higher conversion rates and the avoidance of side reactions have been assumed. Ethanol/ETBE mixtures are known for poor separation by distillation methods because of the given azeotropic properties of the product, which hindered the recycling of unreacted ethanol in the process [12,13]. Another purpose was therefore to optimize the synthesis eliminating high leftover of ethanol in the expected product mixture and to avoid the ETBE/ethanol azeotrope issues. ETBE with a reasonably high quality of $\geq 95 \mathrm{wt} . \%$ has to be obtained to ensure a satisfactory quality for further application as a fuel additive.

\section{Results and Discussion}

\subsection{Initial Screening Using Excess of Ethanol}

The macroreticular structure of Amberlyst-15 imparts unique properties when compared to the homogeneous gel structure of conventional ion exchange resins. Chemical stability is given when employed dry or in nonpolar atmosphere and thus, broadens applications to nonpolar solvent systems in continuous fluidized reactors. The range of application is large and allows mild and highly selective transformations and synthesis in a facile and environmentally friendly manner [20,21]. During etherification the olefin molecule is adsorbed by two sulfonic groups. Carbenium-ion mechanism is proposed and realized at the active sites of the catalyst. A nucleophilic attack by the hydroxyl-oxygen of the ethanol results in the formation of the oxonium-ether species followed by release from the catalyst site (Figure 1) [22,23]. Di- and trimerization of isobutylene are competing reaction pathways. In the case of methanol, it has been found that, in the presence of the alcohol, oligomerization to species heavier than dimers may be greatly reduced. Amount of MTBE fraction is strongly dependent on methanol content as well as reactor design for the provision of efficient cooling to describe an appropriate temperature profile [18]. 


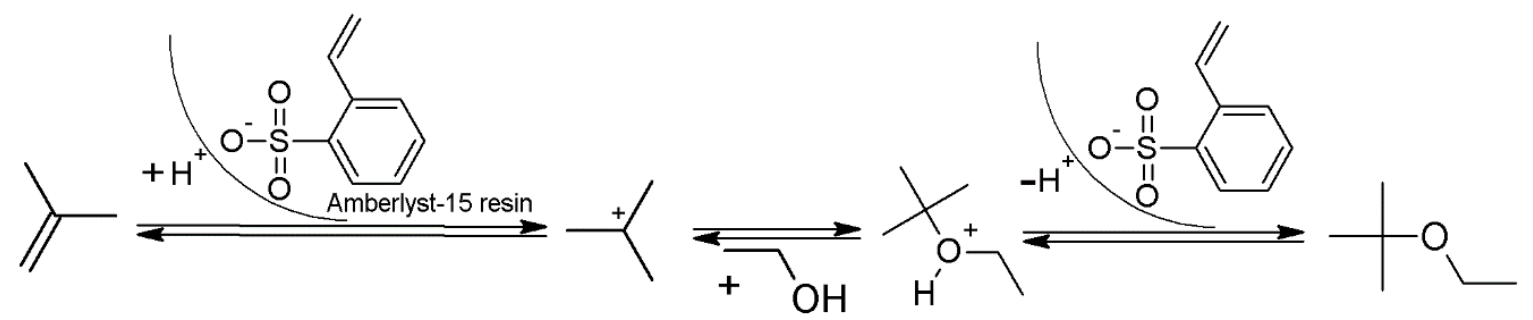

Figure 1. Proposed mechanism of isobutylene activation and conversion via carbenium-ion mechanism at Amberlyst-15 (sulfonic groups at the catalyst resin).

First experiments included the adjustment of the process conditions that were applied for diluted stream to the designed flow reactor system for ETBE formation by using fossil based non-diluted isobutylene [12,24-26]. Accordingly, the loading of Amberlyst-15 catalyst in the reactor catalyst bed has been reduced to easily verify the catalyst volume, and thus, the number of active sites (sulfonic sites). In detail, the catalyst was diluted with inert non-catalytically-active material (glass beads) to avoid favored formation of dimerization (2,4,4-trimethyl-1-pentene, 2,4,4-trimethyl-2-pentene as $\mathrm{C}_{8}$ fraction) and probable oligomerization $\left(\mathrm{C}_{12}\right.$ and $\mathrm{C}_{16}$ derivatives) byproducts (Figure 2$)$ at the given reaction conditions and moreover, to intercept the exothermic nature of the reaction and associated temperature runaways. The ETBE production process was carried out continuously using different ratios of isobutylene and anhydrous ethanol (molar ratio isobutylene to ethanol with $0.25,0.43,0.67$ and 1.0). Moreover, ethanol was used in excess also primarily to avoid the formation of intermolecular products from isobutylene. For every run the same residence time of $\tau=1.8 \mathrm{~min}$ was applied. Besides the variation of the molar ratios of isobutylene and ethanol, the influence of the temperature and pressure was investigated as well.

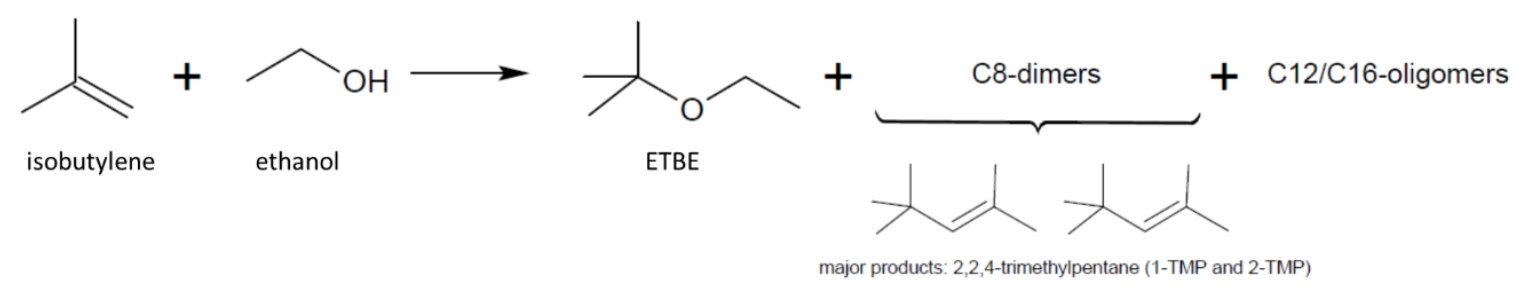

Figure 2. Reaction scheme for the conversion of isobutylene with ethanol. Possible reaction products: ethyl tert-butyl ether (ETBE), $\mathrm{C}_{8}$, and $\mathrm{C}_{12} / \mathrm{C}_{16}$ derivatives.

Table 1 presents the isobutylene conversion profile that is based on fossil feedstock (fossil $\mathrm{EtOH} /$ fossil IBN) adjusted as a function of different process temperatures at the exit of the reactor applying for every run the same total substrate flow of $\mathrm{mL} / \mathrm{min}$. In initial screenings, ethanol was used in multiple excess at $22^{\circ} \mathrm{C}$ and $40^{\circ} \mathrm{C}$ process temperature yielding ETBE in low concentration because of a low isobutylene conversion rate. However, ETBE was obtained as the major product. It is noticeable, that with increasing temperature, the conversion of isobutylene increases, and thus, also the yield of ETBE. Increasing the temperature from $22{ }^{\circ} \mathrm{C}$ to $60{ }^{\circ} \mathrm{C}$, more than the twenty-fold amount of ETBE was obtained with the same isobutylene to ethanol ratio (Table 1, entry 1 and 6). The assays represent a total yield of ETBE between $2.6 \%$ up to $75 \%$. Interestingly, the use of ethanol in excess under higher pressure $(\mathrm{p}=2.4 \mathrm{MPa})$ only resulted in high ETBE selectivity without showing traces of dimerization and/or oligomerization products but to the disadvantage of a low ETBE yield. On the other hand, the continuous formation of ETBE under $\mathrm{p}=1.5 \mathrm{MPa}$ partially showed dimerization products at least at the beginning of the conversion process (Table 2, entry 10). The purity of the ETBE was not determined during this part of investigations. 
Table 1. Data set of the initial screening for continuous processing and ETBE formation using fossil-based isobutylene IBN (constant residence time $\tau=1.8 \mathrm{~min}$ ).

\begin{tabular}{ccccccc}
\hline Entry & $\begin{array}{c}\text { IBN/EtOH } \\
\text { Molar Ratio }\end{array}$ & $\begin{array}{c}\text { Process } \\
\text { Conditions }\end{array}$ & $\begin{array}{c}\text { Flow } \\
(\mathbf{m L} / \mathbf{m i n})\end{array}$ & Yield C8 (\%) & $\begin{array}{c}\text { Formation Rate } \\
\text { ETBE (mol/s/gcat. })\end{array}$ & $\begin{array}{c}\text { Yield ETBE } \\
\text { (\%) }\end{array}$ \\
\hline 1 & $(1: 4.0)$ & $22^{\circ} \mathrm{C} / 2.4 \mathrm{MPa}$ & $5.3: 13.1$ & - & $6.07 \times 10^{-7}$ & 2.6 \\
2 & $(1: 2.3)$ & $22^{\circ} \mathrm{C} / 2.4 \mathrm{MPa}$ & $7.5: 10.9$ & - & $9.92 \times 10^{-7}$ & 3.0 \\
3 & $(1: 1.5)$ & $22^{\circ} \mathrm{C} / 2.4 \mathrm{MPa}$ & $9.5: 8.9$ & - & $1.25 \times 10^{-6}$ & 3.0 \\
4 & $(1: 4.0)$ & $40^{\circ} \mathrm{C} / 2.4 \mathrm{MPa}$ & $5.3: 13.1$ & - & $5.86 \times 10^{-6}$ & 25.1 \\
5 & $(1: 2.3)$ & $40^{\circ} \mathrm{C} / 2.4 \mathrm{MPa}$ & $9.5: 8.9$ & - & $8.42 \times 10^{-6}$ & 20.1 \\
6 & $(1: 4.0)$ & $60^{\circ} \mathrm{C} / 2.4 \mathrm{MPa}$ & $5.3: 13.1$ & - & $1.36 \times 10^{-5}$ & 58.2 \\
7 & $(1: 1.5)$ & $60^{\circ} \mathrm{C} / 2.4 \mathrm{MPa}$ & $7.5: 10.9$ & - & $2.42 \times 10^{-5}$ & 73.2 \\
8 & $(1: 2.3)$ & $60^{\circ} \mathrm{C} / 2.4 \mathrm{MPa}$ & $9.5: 8.9$ & - & $3.07 \times 10^{-5}$ & 73.4 \\
9 & $(1: 1.0)$ & $60^{\circ} \mathrm{C} / 2.4 \mathrm{MPa}$ & $11.4: 7.0$ & - & $3.77 \times 10^{-5}$ & 75.0 \\
10 & $(1: 1.0)$ & $60^{\circ} \mathrm{C} / 1.5 \mathrm{MPa}$ & $11.4: 7.0$ & $9.8^{(b)}$ & $3.97 \times 10^{-5}$ & 79.0 \\
\hline
\end{tabular}

(a) Catalyst filling: $1 / 3$ of the total bulk volume; $2 / 3$ filled with inert material; $117 \mathrm{~mL}$ reactor volume $33 \mathrm{~mL}$ catalyst volume; ${ }^{(b)}$ observed only within the starting fraction.

Table 2. Data set for the optimization of continuous processing for ETBE formation and increasing its final purity (process pressure $2.4 \mathrm{MPa}$, catalyst volume $33 \mathrm{~mL}$ ).

\begin{tabular}{|c|c|c|c|c|c|c|c|}
\hline Entry & $\begin{array}{l}\text { IBN/EtOH } \\
\text { Molar Ratio }\end{array}$ & $\mathrm{T}\left({ }^{\circ} \mathrm{C}\right)^{(\mathrm{a})}$ & $\begin{array}{c}\text { Flow } \\
(\mathrm{mL} / \mathrm{min})\end{array}$ & $\begin{array}{l}\text { Residence } \\
\text { Time (min) }\end{array}$ & $\begin{array}{l}\text { Formation Rate } \\
\text { ETBE }\left(\mathrm{mol} / \mathrm{s} / \mathrm{g}_{\text {cat. }}\right)\end{array}$ & $\begin{array}{c}\text { Yield } \\
\text { ETBE (\%) }\end{array}$ & $\begin{array}{l}\text { Purity ETBE } \\
\text { (wt.\%) }\end{array}$ \\
\hline 1 & $(1: 1.2)$ & 53 & $9.71: 6.88$ & 2.0 & $3.63 \times 10^{-5}$ & 85 & 80 \\
\hline 2 & $(1: 1.0)$ & 55 & $12.91: 8.16$ & 1.6 & $4.83 \times 10^{-5}$ & 85 & 85 \\
\hline 3 & $(1: 0.9)$ & 54 & $13.61: 7.60$ & 1.6 & $4.96 \times 10^{-5}$ & 92 & 88 \\
\hline 4 & (1:0.8) & 52 & $16.05: 6.95$ & 1.4 & $5.54 \times 10^{-5}$ & 98 & 86 \\
\hline
\end{tabular}

\subsection{Optimization of the Continuous Synthesis of ETBE Using Fossil Isobutylene}

Conversions obtained in the reaction system were evaluated as a function of the iso-butylene/ethanol molar ratio and the process temperature at the reactor exit. In a second screening, the molar ratio of isobutylene to ethanol was varied from $0.86,1.0$, and 1.09 to 1.23 including a real flow setting. Here, the temperature was set between $51^{\circ} \mathrm{C}$ to $59{ }^{\circ} \mathrm{C}$ and a defined total flow rate of $16.6-23 \mathrm{~mL} / \mathrm{min}$ was applied resulting in a residence time of $\tau=2.0-2.8 \mathrm{~min}$. This set-up was chosen based on the previous experiments determining the limitations of the catalyst productivity and in order to ensure a sufficient residence time of the reactants. Based on the preliminary experimental results summarized in Table 1, the highest production of ETBE without formation of side products was found to occur with entry 9 at IBN/ethanol ratio of 1:1. However, this led to a higher content of ethanol in the product giving an ETBE purity of only $85 \mathrm{wt.} \%$ shown in a following experiment (Table 2, entry 2). Consequently, a lower ethanol ratio was used to increase the purity of the product mixture with high degree of isobutylene conversion. An optimal ETBE production procedure is attained while using a stoichiometric molar ratio of 1:0.9 (Table 2, entry 3).

The yield of ETBE was directly measured by quantification within the liquid product phase. Since the isobutylene conversion rate is not determined, selectivity can not be determined unambiguously from experimental results. However, we assume $100 \%$ selectivity towards the etherification product: $\mathrm{C}_{8}$ fractions were not detected in this as well as in the following experiments. Rate of ETBE normalized per catalyst weight reflects the formation of the product as a function of the stream of reactants. A dependence on the amount of catalyst is not given. Nevertheless, it can be seen that the stoichiometry of the educts has a considerable influence on the rate of formation.

\subsection{Technology Transfer of the Continuous Synthesis of ETBE Using Bio-Sourced Isobutylene and Production of Sample Amounts}

In the synthesis of bio-sourced ETBE from bio-sourced isobutylene, also the given thermoegulated reactor was used. While setting a constant ethanol flow of $\sim 7.6 \mathrm{~mL} / \mathrm{min}$, the highest 
bio-sourced isobutylene conversion was obtained at reaction temperatures between $53{ }^{\circ} \mathrm{C}$ to $55^{\circ} \mathrm{C}$. Lower temperatures usually result in reduced isobutylene conversion and consequently in reduced ETBE concentration in the liquid product fraction. At the same time, a low ETBE purity was observed with a considerable excess of ethanol in the feed stream since unreacted ethanol accumulates in the product phase (Table 3, entry 4-6). This is also reflected in the formation rate of ETBE. Highest values were obtained for short residence times and equimolar proportions of isobutylene and ethanol.

Table 3. Data set for the optimization of continuous processing for bio-sourced ETBE formation (process pressure 2.4 MPa, catalyst volume $33 \mathrm{~mL}$ ).

\begin{tabular}{cccccccc}
\hline Entry & $\begin{array}{c}\text { IBN/EtOH } \\
\text { Molar Ratio }\end{array}$ & ${\mathbf{T ~}\left({ }^{\circ} \mathbf{C}\right)}^{(\mathbf{a})}$ & $\begin{array}{c}\text { Flow } \\
(\mathbf{m L} / \mathbf{m i n})\end{array}$ & $\begin{array}{c}\text { Residence } \\
\text { Time (min) }\end{array}$ & $\begin{array}{c}\text { Formation Rate } \\
\text { ETBE (mol/s/gcat. }\end{array}$ & $\begin{array}{c}\text { Yield } \\
\text { ETBE (\%) }\end{array}$ & $\begin{array}{c}\text { Purity ETBE } \\
\text { (wt.\%) }\end{array}$ \\
\hline 1 & $(1: 0.9)$ & 54 & $13.61: 7.60$ & 1.6 & $4.96 \times 10^{-5}$ & 92 & 88 \\
2 & $(1: 1.0)$ & 55 & $13.22: 7.52$ & 1.6 & $5.42 \times 10^{-5}$ & 93 & 88 \\
3 & $(1: 1.1)$ & 53 & $9.69: 7.50$ & 1.9 & $3.54 \times 10^{-5}$ & 83 & 79 \\
4 & $(1: 1.5)$ & 52 & $7.96: 7.65$ & 2.1 & $2.80 \times 10^{-5}$ & 80 & 65 \\
5 & $(1: 1.8)$ & 52 & $7.28: 7.65$ & 2.2 & $2.76 \times 10^{-5}$ & 86 & 66 \\
6 & $(1: 3.0)$ & 49 & $4.15: 7.56$ & 2.8 & $1.68 \times 10^{-5}$ & 92 & 49 \\
\hline \multicolumn{8}{c}{ (a) temperature set between at the plant $51{ }^{\circ} \mathrm{C}$ to $58^{\circ} \mathrm{C}}$.
\end{tabular}

Because of irregular gas flows from the bio-sourced isobutylene cylinder that are caused by carbon dioxide impurities in isobutylene, the flow rate of the feedstock had to be continuously adjusted to the given fluctuations and result in both too low and too high isobutylene flows. This caused temperature fluctuations that could not be compensated due to the inertia of the temperature control system at the reactor. Hot spot formation and temperature runaways are likely to take place, since no dilution of the feed stream was provided. These can only be compensated inadequately and explains the slightly fluctuating temperature profile in the reactor. Best yield and purity of ETBE was reached using process parameters determined previously, namely at IBN/ethanol molar ratio of 1:0.9 and of 1:1.0 (Table 3, entry 1 and 2). At this point, it must be noted that the operation of the reaction system has been adapted by permanent manipulation to the given $\mathrm{CO}_{2}$ stream. Finally, a continuous flow of isobutylene could be achieved temporarily, resulting in comparable yield and purity levels, as in the fossil feed. This short-term steady-state condition was used as the reference data set.

Optimized conditions (IBN/EtOH molar ratio $=1: 0.9$ and $\mathrm{T}=53^{\circ} \mathrm{C}$ ) were applied to produce more than $2.0 \mathrm{~L}$ of $100 \%$ renewable ETBE from bio-sourced isobutylene and bio-sourced ethanol in good yield (97\%) but moderate quality of $89 \mathrm{wt.} \%$ (Table 4, entry 1). In order to increase the ETBE purity, a second campaign was started to convert bio-sourced isobutylene accompanied by an increase in the IBN/ethanol molar ratio to 1:0.4 (Table 4, entry 2). The flow rate of isobutylene was doubled to suppress enrichment of ethanol in the liquid product phase and suppress the formation of dimerization products; mainly for the reason of being able to realize a continuous isobutylene stream from the cylinder. However, an entirely steady reaction was not observed, resulting in a temperature fluctuation between $51{ }^{\circ} \mathrm{C}$ to $58^{\circ} \mathrm{C}$ within the reactor. Dilution of the catalysts reduces the number of active sites. However, only dilution of the substrate by an inert feed, such as alkanes, allow a constant temperature distribution in the catalyst bed and the avoidance of hot spots, since alkanes are adsorbed uniformly on the catalyst surface and block active sites. 
Table 4. Data set and process parameters for $100 \%$ renewable ETBE production in liter-scale (process pressure 2.4 MPa, catalyst volume $33 \mathrm{~mL}$ ).

\begin{tabular}{ccccccccc}
\hline Entry & $\begin{array}{c}\text { IBN/EtOH } \\
\text { Molar Ratio }\end{array}$ & $\mathbf{T}\left({ }^{\circ} \mathbf{C}\right){ }^{(\mathbf{a})}$ & $\begin{array}{c}\text { Flow } \\
(\mathbf{m L} / \mathbf{m i n})\end{array}$ & $\begin{array}{c}\text { Residence } \\
\text { Time } \\
(\mathbf{m i n})\end{array}$ & $\begin{array}{c}\text { Formation } \\
\text { Rate ETBE } \\
\left(\mathbf{m o l} / \mathbf{s} / \mathbf{g}_{\text {cat. }}\right)\end{array}$ & $\begin{array}{c}\text { Yield } \\
\text { ETBE } \\
(\mathbf{\%})\end{array}$ & $\begin{array}{c}\text { Purity ETBE } \\
(\mathbf{w t . \%})\end{array}$ & $\begin{array}{c}\text { Water } \\
\text { Content } \\
(\mathbf{w t .} \%)\end{array}$ \\
\hline 1 & $(1: 0.9)$ & 53 & $13.09: 7.56$ & 1.6 & $4.77 \times 10^{-5}$ & 97 & 89 & - \\
2 & $(1: 0.4)$ & 54 & $25.97: 7.10$ & 1.0 & $4.26 \times 10^{-5}$ & 34 & $84 / 99$ (b),(c) & $0.02 / 0.50$ \\
\hline
\end{tabular}

(a) Temperature set at the plant between $51{ }^{\circ} \mathrm{C}$ to $58{ }^{\circ} \mathrm{C}$; (b) after water extraction of the ETBE product; ${ }^{\text {(c) }} 4.2 \mathrm{~L} \mathrm{ETBE}$ solution were purified to give $2.9 \mathrm{~L}$ ETBE with $99 \mathrm{wt} . \%$.

This mode of reaction led to incomplete conversion of isobutylene with a yield of ETBE, relative to isobutylene of only $34 \%$. Isobutylene was released from the reactor unconverted. Dimerization and oligomerization to higher olefins were not observed in the product phase.

Purification methods were evaluated to subsequently increase ETBE purity to a reasonable quality for further application tests. After post-distillation of the ETBE product at reduced pressure (390 mbar) at moderate temperature $\left(50^{\circ} \mathrm{C}\right)$, water extraction was applied in order to transfer the residual ethanol into the water phase and further increase the ETBE concentration beyond the ETBE/ethanol azeotrope. This purification procedure was successfully carried out and led to $2.9 \mathrm{~L}$ of a final solution with $\mathrm{w}_{\mathrm{ETBE}}$ $\geq 99 \mathrm{wt} . \%$. This corresponds to an overall yield of $28 \%$. At the same time, the water content in the solution rises from $0.02 \mathrm{wt} . \%$ to $0.50 \mathrm{wt} . \%$. One-cylinder engine testing results confirmed that the renewable gasoline meets the requirements and it has very high performances. Start of the on-road testing phase for renewable ETBE is being announced [27].

\section{Materials and Methods}

\subsection{Chemicals and Equipment}

Fossil-based isobutylene (IBN) (3.0; $\mathrm{w}_{\mathrm{IBN}} \geq 99$ wt.\% and $\mathrm{w}_{\mathrm{CO} 2} \leq 0.1$ vol.\%; Linde, Leuna, Germany) and a very early sample of bio-sourced isobutylene provided by Global Bioenergies (Leuna, Germany) with an IBN concentration of $\mathrm{w}_{\mathrm{IBN}}=92.8 \mathrm{vol} . \%$ and a carbon dioxide concentration of $\mathrm{w}_{\mathrm{CO} 2}$ $=6.4 \mathrm{vol} . \%$ was used and handled as a liquefied gas. Bio-sourced absolute ethanol was purchased from VWR Chemicals (Dresden, Germany) ( $\geq 99.8 \mathrm{wt} . \%$ ) and Merck (Darmstadt, Germany) ( $\geq 99.9 \mathrm{wt.} \%$ ), respectively. The reaction was heterogeneously catalyzed while using Amberlyst-15 (hydrogen form; Sigma-Aldrich, (Taufkirchen, Germany)). To dilute the catalyst's loading, inert glass beads (5 mm, VWR (Dresden, Germany)) were used with a mass ratio of catalyst to inert material of 1:3 (volume ratio catalyst $/$ glass beads $=2.57$ ) and catalyst volume $\mathrm{V}_{\text {cat }}=33 \mathrm{~mL}$.

The catalytic reaction was carried out in a continuous-flow reactor system (Figure 3). The reactor consisted of a countercurrent heated flow tube. The heated section was about $60.5 \mathrm{~cm}$ and the inner diameter $\frac{3}{4}$ " $(19.05 \mathrm{~mm})$. The heating medium was externally tempered and the process temperature was measured approx. $20 \mathrm{~cm}$ above the upper end of the heating jacket. The total reactor volume was defined to be $117 \mathrm{~mL}$. Two high-pressure piston pumps were used to pump individual liquid feeds into the reactor system, controlling the flow rates from each pump. The pressure adjustment was carried out via a manual pressure valve that was mounted at the reactor outlet. 


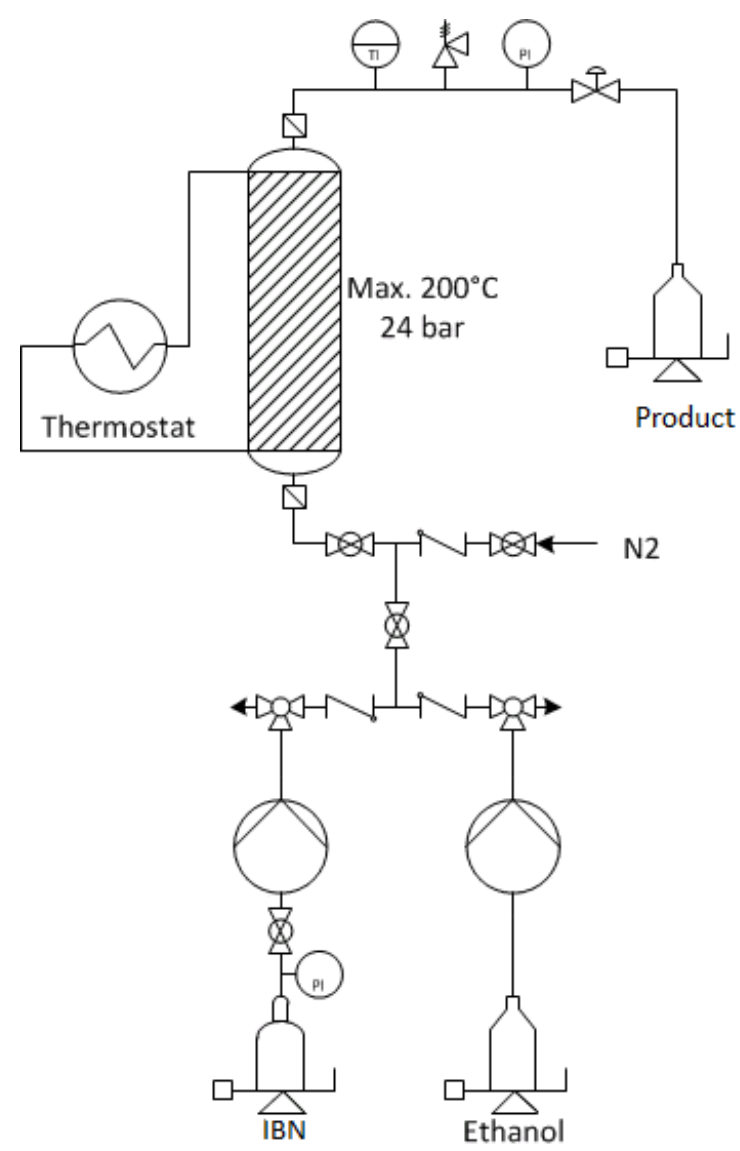

Figure 3. Flow sheet of the continuous flow reactor system to process isobutylene (IBN) and ethanol.

\subsection{Methods for Catalysis and Purification}

After connecting the isobutylene cylinder and the ethanol feed, the system was first purged with nitrogen at $60{ }^{\circ} \mathrm{C}$ and subjected to a pressure test of up to 26 bar for $30 \mathrm{~min}$. Subsequently, the pressure was adjusted to 24 bar and the ethanol flow started. As soon as ethanol emerged from the reactor outlet into the collecting vessel, isobutylene has been dosed and the measurement was started. Three pre-flows were collected for an interval of $10 \mathrm{~min}$ to ensure that isobutylene was fully circulated through the reactor space and the catalyst was activated. If the reaction stagnated due to too much gas in the isobutylene cylinder, the flow rates were adjusted and/or the supply of isobutylene was vented. Various ratios on molarities of isobutylene to ethanol were adjusted by regulation of the pump flow rate. Residence time $\tau$ was calculated as quotient of catalyst volume in $\mathrm{mL}$ and flow rate of both substrates (ethanol and isobutylene) in $\mathrm{mL} / \mathrm{min}$. The yield of the product was determined as the amount of ETBE in the product solution always related to the deficient part of starting material in the feedstock solution. It is defined as the amount of ETBE in the isolated liquid product determined by gas-chromatography analysis. ETBE formation rate was derived from that taking into account $\varrho$ (catalyst $)=1.2 \mathrm{~g} / \mathrm{mL}$ at $25^{\circ} \mathrm{C}$ and $\varrho$ (isobutylene $)=0.5879 \mathrm{~g} / \mathrm{mL}$ in liquid phase.

The ETBE/ethanol mixture was post-distilled at $50{ }^{\circ} \mathrm{C}$ and under reduced pressure at $390 \mathrm{mbar}$ removing traces of isooctene, oligomerization products, and flushed catalyst sulfonylic acid residues. Selected samples from bio-sourced ETBE production have been further purified by water extraction. Here, ETBE samples were stirred with a 1:3 mass ratio (determined with Gibbs's phase diagram) with deionized water in the batch reactor $(10 \mathrm{~L}$ borosilicate glass reactor equipped with a KPG stirrer) for $10 \mathrm{~min}$. Phase separation resulted in the isolation of the purified ETBE sample without further treatment. 


\subsection{Analytical Methods}

Products were analyzed using instrumental gas-chromatography methods. A device from Agilent Technologies (Waldbronn, Germany), type 7890A as a gas chromatograph with a post-coupled mass spectrometer (5975c VL MSD with Triple Axis Detector, (Agilent Technologies (Waldbronn, Germany)) and the 7693 auto sampler was used for the quantitative measurement of the samples. As a separation column, a HP-5MS column was employed. O-xylene was used as an internal standard. Conversion rates and yields were determined from a molar mass balance in the reactor system. Water content was determined by Karl Fischer titration (KF; 803 Ti Stand from Metrohm (Filderstadt, Germany)).

\section{Conclusions}

The use of fermentative produced isobutylene as undiluted substrate in a solvent-free catalysis was demonstrated for the first time. It was shown that bio-soured isobutylene can be implemented directly in process chains for the production of fuels and fuel additives. Direct etherification with bio-sourced ethanol results in the production of fully renewable ethyl tert-butyl ether (ETBE) in yields up to $97 \mathrm{~mol} \%$ ETBE applying the acidic ion exchanger Amberlyst-15. Hot-spot formation and temperature runways probably occurred during the reaction, although the catalyst was diluted. Deactivation of the catalyst by catalyst-poisons was not observed. However, occasions of a gradual deterioration in the eligibility of the biogenic isobutylene ensued. The reason for this is the presence of gaseous impurities, in particular, of dissolved carbon dioxide in the isobutylene cylinder, which makes the continuous processing of the liquid substrates more difficult. Plant-specific modifications are required to suppress gas formation, while feeding the liquefied and $\mathrm{CO}_{2}$ containing gas during reaction.

Finally, product mixtures in liter scale could be synthesized by continuous process adaption with purities up to $89 \%$ and yields of $97 \%$. Residues of ethanol were successfully removed from the ETBE phase by evaporation and water extraction giving ETBE purities of $99 \mathrm{wt.} \%$, and thus, providing satisfactory quality for application as a fuel additive in engine-testing.

Author Contributions: M.T. and D.P.-H. conceived and designed the research process; T.W. and A.H. performed the catalytic trails; U.J. performed and provided data related to the purification process. A.B. contributed feed material and product specification as well as scientific advice. All authors revised the manuscript in the parts related to their contribution.

Funding: This research was partially funded by Global Bioenergies GmbH. In addition, the authors gratefully thank and acknowledge the Federal Ministry of Education and Research (BMBF) for co-funding and financially support this project named TG2, Bio-isobutylene derived fuel additive (VP 2.17 Bio-FAA, support code 031B0214) as part of the leading edge cluster BioEconomy.

Conflicts of Interest: The authors declare no conflict of interest. The funders were involved in the design and coordinated of the study and provided isobutylene and specifications for ETBE; they were not involved in the collection, analyses, or interpretation of data and in the decision to publish the results.

\section{References}

1. EU-Regulation Number 510/2011. Available online: https:/ / eur-lex.europa.eu/legal-content/EN/TXT/ ?uri=celex\%3A32011R0510 (accessed on 2 November 2018).

2. US EPA, Office of Water (OW). Chapter 13 (MTBE) of Regulatory Determinations Support Document for Selected Contaminants from the Second Drinking Water Contaminant Candidate List (CCL 2). July 2008. Available online: https:/ / www.epa.gov/ccl/regulatory-determination-2-contaminants-second-drinkingwater-contaminant-candidate-list (accessed on 2 November 2018).

3. US EPA. Federal Register/Rules and Regulations, 71, 106, 2006. Available online: https: / / www.federalregister.gov/documents/2006/04/03/06-3132/regulation-of-fuel-and-fuel-additivesgasoline-and-diesel-fuel-test-methods (accessed on 2 November 2018).

4. Bundesgesetzblatt Teil 1, Nr. 41. Gesetz zur Änderung der Förderung von Biokraftstoffen, 19 July 2009. Available online: https://www.bgbl.de/xaver/bgbl/start.xav?start=\%2F\%2F*[\%40attr_id \% 3D\%27bgbl109s1804.pdf\%27]\#_bgbl_\%2F\%2F*\%5B\%40attr_id\%3D\%27bgbl109s1804.pdf\%27\%5D_ _1541147863998 (accessed on 2 November 2018). 
5. Hart Energy Publishing and its Global offices, Bio-ETBE: The Right Road to High Quality 21st Century Motor Fuels. 2008. Available online: https:/ / de.scribd.com/document/148045860/2008-Hart-Publicationon-Bio-ETBE. (accessed on 7 February 2017).

6. Global Bioenergies. First Production in History of Fully Renewable ETBE, 7t February 2017. Available online: http:/ / www.global-bioenergies.com/first-production-in-history-of-fully-renewable-etbe/?lang=en (accessed on 2 November 2018).

7. Sun, J.; Liu, C.; Wang, Y.; Martin, K.; Venkitasubramanian, P. Process for Making Biobased Fuel Additives. Patent US 020150239812 A1, 27 August 2015.

8. Marliere, P. Method for the Enzymatic Production of 3-hydroxy-3-methylbutyric Acid from Acetone and Acetyl-CoA. Patent EP 2295593 A1, 16 March 2011.

9. Marliere, P. Production of Alkenes by Enzymatic Decarboxylation of 3-hydroxyalkanoic Acids. Patent WO 2010001078 A3, 1 July 2010.

10. Marliere, P.; Allard, M. Method for Producing Isobutylene from 3-methylcrotonyl-CoA. Patent WO 2016042011 A1, 24 March 2016.

11. Allard, M.; Anissimova, M.; Marliere, P. Methods for Producing Isobutylene from 3-methylcrotonic Acid. Patent WO 2017085167 A2, 26 May 2017.

12. Weber de Menezes, E.; Cataluna, R. Optimization of the ETBE (ethyl tert-butyl ether) production process. Fuel Process. Technol. 2008, 89, 1148-1152. [CrossRef]

13. Yee, K.F.; Mohamed, A.R.; Tan, S.H. A review on the evolution of ethyl tert-butyl ether(ETBE) and its future prospects. Renew. Sustain. Energy Rev. 2013, 22, 604-620. [CrossRef]

14. Shpantseva, L.V.; Aksenow, V.I.; Komarov, S.V.; Yu, A.; Tyulentseva, L.E. Method for Manufacturing High-octane Additive to Gasoline Containing Ethyl tert-butyl Ether. Patent RU 2391329 C2, 10 June 2010.

15. Goto, S. Method for Synthesizing ETBE. JP 2005162669A, 23 June 2003.

16. Assabumrungrat, S.; Kiatkittipong, W.; Sevitoon, N.; Praserthdam, P.; Goto, S. Kinetics of liquid phase synthesis of ethyl tert-butyl ether from tert-butyl alcohol and ethanol catalyzed by $\beta$-zeolite supported on monolith. Int. J. Chem. Kinet. 2002, 34, 292-299. [CrossRef]

17. Jensen, K.L.; Datta, R. Ethers from Ethanol. 1. Equilibrium Thermodynamic Analysis of the Liquid-Phase Ethyl tert-Butyl Ether Reaction (ETBE). Ind. Eng. Chem. Res. 1995, 34, 392-399. [CrossRef]

18. Girolamo, M.D.; Lami, M.; Marchionna, M.; Pescaroll, E.; Tagliabue, L.; Ancillotti, F. Liquid-phase etherification/dimerization of isobutylene over sulfonic acid resins. Ind. Eng. Chem. Res. 1997, 36, 4452-4458. [CrossRef]

19. Krivan, E.; Valkai, I.; Hancsok, J. Investigation of production of motor fuel components on heterogeneous catalysts with oligomerization. Top. Catal. 2013, 56, 831-838. [CrossRef]

20. Robert, K.; Meitzner, E.A.; Oline, J.A.; Fisher, S.A.; Norman, F. Characterization of Amberlyst-15. macroreticular sulfonic acid cation exchange resin, Ind. Eng. Chem. Prod. Res. Dev. 1962, 1, 140-144.

21. Rammohan, P.; Taradas, S.; Shampa, K. Amberlyst-15 in organic synthesis. Top. Catal. 2013, 56, 831-838.

22. Alcantara, R.; Alcantara, E.; Canoira, L.; Franco, M.J.; Herrera, M.; Navarro, M. Trimerzation of isobutene over Amberlyst-15 catalyst. Reac. Funct. Polym. 2000, 45, 19-27. [CrossRef]

23. Balakrishnan, M.; Sacia, E.R.; Bell, A. T Etherfication and reductive etherfication of 5-(hydroxymethyl)fufural: 5-(alkoxymethyl)fufurals and 2,5-bis(alkoxymethyl)furans as potential bio-diesel candidates. Green Chem. 2012, 14, 1626-1634. [CrossRef]

24. Giwa, A. Sensitivity Analysis of ETBE Production Process Using Aspen PLUS, Sensitivity Analysis of ETBE. Production Process. Using Aspen PLUS 2015, 3, 293-303.

25. Tau, L.-M.; Davis, B.H. Acid catalyzed formation of ethyl tertiary butyl ether (ETBE). Appl. Catal. 1989, 53, 263-271. [CrossRef]

26. Bakshi, A.; Jones, E.M.; Strain, B.A. Process for the Preparation of ETBE. Patent US 5248836A, 28 September 1993.

27. Global Bioenergies. First Car Driving with Global Bioenergies' Renewable Gasoline. 5 April 2018. Available online: http:/ / www.global-bioenergies.com/first-car-driving-with-global-bioenergies-renewable-gasoline/ ?lang=en (accessed on 2 November 2018).

(C) 2018 by the authors. Licensee MDPI, Basel, Switzerland. This article is an open access article distributed under the terms and conditions of the Creative Commons Attribution (CC BY) license (http://creativecommons.org/licenses/by/4.0/). 